\title{
Sexual assault: Exploring real-time consequences the next day and in subsequent days
}

\author{
Todd Kashdan · David J. Disabato · Patrick E. McKnight · Kerry C. Kelso \\ MarLa Lauber · Fallon R. Goodman
}

\begin{abstract}
Approximately 15-20\% of adult women in the United States have been sexually assaulted. Given the high prevalence of sexual assault, it becomes increasingly important to understand immediate responses to sexual assault. A lack of information prior to sexual assaults contributes to a literature that is unable to showcase the presence and amount of change. A tendency to rely on comparisons between people, instead of the collection of multiple moments of a single person over time, will continue to point toward imprecise, statistical "average" reactions to sexual assaults. Prior methodological approaches lead to broad overgeneralizations about sexual assault survivors that may undermine their unique experiences in the aftermath of an assault. The present study extends the existing literature with access to unprecedented data gathered on the days before and immediately after someone survived a sexual assault. To our knowledge, there are no studies capturing prior functioning and near immediate psychological reactions of sexual assault survivors. In the present study, each night over the course of three weeks, we asked college students ( $n=186)$ to report on their sexual activity and well-being. Six women and one man reported being sexually assaulted at least once. We examined psychological experiences on the days before and after sexual assaults (including negative and positive affect, social anxiety, self-esteem, emotion expressive suppression, and cognitive reappraisal). To examine sexual assault reactions, we used various descriptive approaches. Our results suggest that before and after being assaulted, survivors showed no consistent response in subjective well-being. We failed to find a prototypical psychological profile. Despite the small sample, our results raise important questions and offer future hypotheses about individual differences in responses to sexual assault.
\end{abstract}

Keywords: rape, sexual assault, well-being, wellbeing, emotion regulation, social anxiety, resilience

\section{Introduction}

One out of five American women are sexually assaulted in their lifetime and nearly two million women are sexually assaulted each year (Breiding et al., 2014; Waechter \& Ma, 2015). The impact of sexual assault appears to be both widespread and enduring. However, our knowledge is primarily limited to information gathered from survivors long after the trauma occurred and/or studies that do not capture pre-assault functioning. The sexual assault literature has been dominated by cross-sectional methods from which scientists repeatedly uncovered a link between a history of sexual trauma and current psychological problems. With this

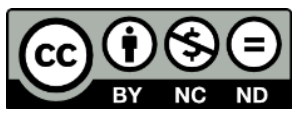

Copyright belongs to the author(s) www.internationaljournalofwellbeing.org 
methodological approach, temporal precedence cannot be established. Using longitudinal investigations, scientists gain a better understanding of sexual assault's effects on survivors.

Of the longitudinal research available, all but one study (Frazier, Conlon, \& Glaser, 2001) collected data from survivors at monthly and yearly intervals following the trauma. While this approach can delineate longer term patterns of mental health symptoms, well-being, and impairment (e.g., Dworkin, Ullman, Stappenbeck, Brill, \& Kaysen, 2018; Naragon-Gainey, Simpson, Moore, Varra, \& Kaysen, 2012), there are unanswered questions about the impact of sexual assault in the immediate aftermath. Remarkably, one study assessed survivors as soon as two weeks post-assault (Frazier, Conlon, \& Glaser, 2001), although this study did not capture pre-assault functioning. Daily diary studies can help scientists disentangle short-term perturbations and resilience trajectories from disorder to recovery (Bonanno, 2013; Steenkamp et al., 2012; Steenkamp, Litz, Dickstein, Salters-Pedneault, \& Hofmann, 2013).

To best understand how people respond to trauma, researchers need to capture survivors' psychological state prior to the trauma. Research on resilience has increasingly moved away from identifying a resilient "personality" or "trait" and instead conceptualized resilience as an interaction between a person's resources/strengths and the events they experience that is sensitive to context (Bonanno \& Diminich, 2013; Norris, Stevens, Pfefferbaum, Wyche, \& Pfefferbaum, 2008; Shiner \& Masten, 2012). In this way, resilience to trauma is a process, not a capacity - a person is resilient when despite the presence of a negative life event/trauma there is no sustainable decline in their well-being (Goodman, Disabato, Kashdan, \& Machell, 2017)

Researchers who study traumatic events that occur at random such as natural disasters, motor vehicle accidents, and sexual assaults are limited to capitalizing on existing, ongoing studies that include sufficient and relevant data before and after the event. To our knowledge, only two studies assessed people prior to and after being sexually assaulted (Carey, Norris, Durney, Shepardon, \& Carey, 2018; Krahé \& Berger, 2017). As such, we expanded our review to include research that captured pre- and post-functioning following other types of traumatic events to help understand trajectories following sexual assault.

Recent theoretical models suggest there is remarkable heterogeneity following traumatic events. Of the many possible trajectories of functioning post-trauma, an increasing amount of evidence suggests that the most common trajectory is resilience. Westphal and Bonanno (2007) describe resilience as "continu[ing] to be able to fulfill personal and interpersonal demands even in the face of considerable adversity" (p. 420). A number of longitudinal studies of combat related trauma support this claim. In one study of 120 United States soldiers deployed on a peacekeeping mission to Kosovo, 84\% displayed a resilient response post-deployment (Dickstein, Suvak, LItz, \& Adler, 2010); a study of 366 Danish soldiers deployed to Afghanistan found a similar postdeployment resilience trajectory rate of $70 \%$ (Bersten et al., 2012; see also Andersen, Karstoft, Bertelsen, \& Madsen, 2014); and a study of United States Marines deployed to Afghanistan found a resilient trajectory rate of $79 \%$ (Nash et al., 2015).

In contrast to a resilience narrative, Infurna and Luthar (2018) suggest recovery is the most common reaction to traumatic events - where survivors report high levels of initial distress that decline over time until survivors return to baseline functioning. Independent of the debate as to whether recovery or resilience dominates, attention has also been given to post-traumatic growth, where traumatic events are followed by positive life changes from a greater sense of appreciation for what one has to the presence of healthy, supportive relationships to a recognition of pre-existing, inadequately tested, psychological strength (Tedeschi \& Calhoun, 1996; see Jayawickreme \& Blackie [2014] for a review). Others have described adaptive posttrauma changes as "psychological improvement" - characterized by decreases in mental health 
symptoms rather than changes in personality. For example, in a study of female survivors of the 2007 Virginia Tech University shooting, 13.2\% reported an improvement in anxiety symptoms and $7.4 \%$ an improvement in depression symptoms one year after the event (Mancini, Littleton, \& Grills, 2016). While these perspectives on recovery, resilience, and growth describe what occurs in the aftermath of trauma in general, are they applicable to sexual assault?

Research conflicts as to whether resilience and posttraumatic growth are typical responses to sexual trauma. Beginning at one-month post-assault, researchers identified recovery from significant distress as the modal reaction to sexual trauma (Steenkamp et al., 2012). Perhaps, after experiencing sexual assault, survivors are more likely to experience intense, immediate distress that dissipates over time. A review of 17 articles found that $25-67 \%$ of sexual assault survivors reported some form of post-traumatic growth, including heightened concern for others in similar situations, improved relationships with family members, and a greater appreciation for life (Ulloa, Guzman, Salazar, \& Cala, 2016). One study found that positive life changes as soon as 2 weeks post-assault predicted subsequent psychological growth 12 months later (Frazier, Conlon, \& Glaser, 2001). In other studies, survivors reported increased levels of depression, anxiety, disordered sleeping and eating, substance use problems, and suicidality following assault (Dworkin, Menon, Bystrynski, \& Allen, 2017; Thurston, Chang, Matthews, von Känel, \& Koenen, 2018). Prevalence estimates suggest that anywhere from $17-65 \%$ of survivors develop posttraumatic stress disorder (PTSD; Campbell, Dworkin, \& Cabral, 2009). At the very least, prior findings illustrate a variety of responses to sexual assault, including fluctuations in positive and negative outcomes.

Given the pervasiveness of sexual assault and the varied impact on survivors, it becomes increasingly important to understand immediate responses to sexual assault. Lack of information prior to sexual assaults contributes to the presence of variable-centric rather than person-centric research (Kashdan \& McKnight, 2011). As long as studies focus on between-person data, and not the multiple moments of events and reactions to them by a single person over time, the literature will continue to point toward an imprecise, statistical "average" sexual assault reaction. This methodological approach risks leading to broad overgeneralizations about sexual assault survivors that may undermine their unique experiences in the aftermath of an assault.

The present study extends the existing literature with access to unprecedented data gathered on the days before and immediately after someone survived a sexual assault. These data allow for close examination of individual behavioral changes in response to a sexual assault. We also conducted a comparison of sexual assault survivors with non-assaulted peers using a variety of daily measures of individual difference spanning psychological suffering and well-being. Specifically, we included positive and negative affect to capture the affective components of subjective well-being (Diener, 1984); meaning in life to assess for changes in one's interpretation of their place in the world; self-esteem to assess for changes in beliefs about the self; and social anxiety to assess for changes in worries about other people's perceptions. Thus, our measures capture a variety of intrapersonal and interpersonal processes that may be relevant in the aftermath of assault.

Before proceeding, we need to clarify our intentions regarding the use of data collected prior to the onset of sexual assaults. Due to the size of our sample, the present study is descriptive, rather than predictive (Rozin, 2001). Consistent with literature suggesting a number of different trajectories-resilience or otherwise-following a trauma, we anticipated that upon closely inspecting individuals in the days surrounding sexual assault, a heterogeneous range of responses would emerge. Regardless of emotional disturbances recorded prior to the assaults, our findings should not be interpreted as placing any responsibility on survivors. To the 
contrary, our intention in analyzing well-being prior to the assault is to understand resilience to trauma. This approach is similar to research on resilience to unexpected traumas (e.g., terrorist attacks; Fredrickson, Tugade, Waugh, \& Larkin, 2003) and consistent with a process-based operationalization of resilience (e.g., Goodman, Disabato, Kashdan, \& Machell, 2017). We hope that these descriptive results shed light on the complexity of human reactions to sexual assault.

\section{Method}

\subsection{Participants}

Data were collected from 186 university students (133 women, 40 men, 13 with missing data). Age range of the initial sample ranged from 18 to 63 years old $(\mathrm{M}=24.02, \mathrm{SD}=9.26)$, the racial/ethnic composition was 57.2\% White, 13.8\% Latino/Hispanic, 11.8\% Asian, $7.2 \%$ African American, 2\% Middle Eastern, $0.7 \%$ Native American, and 7.2\% other, and the majority (94\%) identified as heterosexual with $2.6 \%$ as homosexual, $2.6 \%$ as bisexual, and one person indicating "other". In our sample, $63.8 \%$ indicated being in a monogamous romantic relationship.

We arrived at a final sample of seven participants (six women, one man) who indicated being subjected to nonconsensual sex at least once during their respective daily diary assessment period - confirmed with a close data inspection (see Results section). Our first selection criterion was based solely on whether the participant indicated non-consensual sex during the course of the three week study. Our second criterion focused on whether there is evidence that they misinterpreted what non-consensual sex meant in our survey. That is, is there evidence that they did something sexual but not with a partner such as pornography, strip clubs, masturbating, etc on each day that they endorsed non-consensual sex? These criteria are detailed in Table 1.

Table 1. Details on each participant endorsing at least one sexual assault during the daily diary assessment period

\begin{tabular}{l|l|l}
\hline $\begin{array}{l}\text { Random } \\
\text { ID }\end{array}$ & $\begin{array}{l}\text { Final } \\
\text { Sample? }\end{array}$ & Available Evidence \\
\hline 1 & Y & On day 14 of the study, she reported non-consensual sex. \\
\hline 2 & Y & $\begin{array}{l}\text { On day 2 of the study, she reported non-consensual sex. On the same day, } \\
\text { she reported an additional consensual experience. }\end{array}$ \\
\hline 3 & Y & On day 10 of the study, she reported non-consensual sex. \\
\hline 4 & Y & On day 29 of the study, she reported non-consensual sex. \\
\hline 6 & Y & On day 17 of the study, she reported non-consensual sex. \\
\hline 7 & Y & $\begin{array}{l}\text { On day 19 of the study, he reported non-consensual sex. } \\
\text { On day 1 of the study, she reported non-consensual sex. On the same day, } \\
\text { she reported having an additional consensual sexual experience. }\end{array}$ \\
\hline & No & $\begin{array}{l}\text { In the baseline sexual history questionnaire, she reported having two } \\
\text { ongoing, regular sex partners. In the daily diary portion of the study, she } \\
\text { reported non-consensual sex on days 10, 11, 17, 18, 20, and 21. We } \\
\text { examined free-text responses to episodes that led her to feel angry on } \\
\text { days she endorsed non-consensual sex. Her responses included: "Still } \\
\text { haven't finished overdue history paper", "nothing", "nothing at all", } \\
\text { "today was FABULOUS!!!!", "I got in a fistfight with Laura and my eye } \\
\text { hurts", and "today was absolutely perfect". Because of the presence of }\end{array}$ \\
\hline
\end{tabular}




\begin{tabular}{|c|c|c|}
\hline & & $\begin{array}{l}\text { diametrically opposed responses on the same day, multiple times, we } \\
\text { believe the data are invalid and removed her from the final sample. }\end{array}$ \\
\hline 9 & No & $\begin{array}{l}\text { In the baseline sexual history questionnaire, he claimed to be abstaining } \\
\text { from sex due to his and his family's values. He reports satisfaction with } \\
\text { the (lack of) sex in his life (a rating of } 6 \text { on a } 7 \text {-point scale). He reports } \\
\text { having consensual sex on the first days } 1 \text { and } 2 \text { of the study, and non- } \\
\text { consensual sex on days } 3,4,5,6,8,19 \text {, and } 20 \text {. Because of this atypical } \\
\text { profile, we examined follow-up questions on days he reported being } \\
\text { sexually assaulted. On days } 3,4,5,6,8,19 \text {, and } 20 \text {, he reported } \\
\text { masturbating alone and feeling satisfied when masturbating (ratings } \\
\text { ranged from } 4-6 \text { on a 7-point scale). He reported having sex with another } \\
\text { person on days } 1 \text { and } 2 \text { but not on days when he endorsed both } \\
\text { masturbation and non-consensual sex. We believe he mistakenly } \\
\text { endorsed non-consensual sex when masturbating alone because this act } \\
\text { does not require anyone's consent. We believe the data are invalid and } \\
\text { removed him from the final sample. }\end{array}$ \\
\hline 10 & No & $\begin{array}{l}\text { In the baseline sexual history questionnaire, he claimed to be abstaining } \\
\text { from sex. On day } 16 \text { of the study, he reported non-consensual sex. On the } \\
\text { same day } 16 \text { he also reported watching internet pornography and } \\
\text { masturbating alone and feeling satisfied when masturbating (rating of } 5 \\
\text { on a 7-point Likert scale). While believe he mistakenly endorsed non- } \\
\text { consensual sex when masturbating alone because this act does not } \\
\text { require the consent of any party. He reported having sex with another } \\
\text { person on day } 1 \text { but not on the days when he endorsed both self- } \\
\text { stimulation and non-consensual sexual activity. We believe the data are } \\
\text { invalid and removed him from the final sample. }\end{array}$ \\
\hline 11 & No & $\begin{array}{l}\text { In the baseline sexual history questionnaire, he claimed to be abstaining } \\
\text { from sex due to religious reasons. On day } 21 \text { of the study, he reported } \\
\text { non-consensual sex. On the same day } 21 \text { he also reported going to a strip } \\
\text { club and paying for sex. We believe he mistakenly endorsed non- } \\
\text { consensual sex when paying for sex at the strip club believing that sex } \\
\text { workers are not asked to give consent. He did not report sexual activity } \\
\text { on any other day during the assessment period. We believe the data are } \\
\text { invalid and removed them from the final sample. }\end{array}$ \\
\hline
\end{tabular}

Note. Due to the sensitive nature of this topic and the possibility that results are misinterpreted, we were meticulous in ensuring full confidence that our final sample of participants endorsed a sexual assault. This specific study was reviewed and approved by the Human Subject institutional review board at George Mason University before the study began (approval number \#4511).

\subsection{Procedure}

We recruited participants through campus flyers, online advertisements, and an online portal for student seeking to participate in research through the Psychology Department. Participants were informed during the consent process that the purpose of the study was to better understand how people experience emotions, sexuality activities, and daily life events. Upon completion of the daily diary portion, participants received raffle tickets for one of ten $\$ 25$ gift certificates.

Participants completed a 1.5-hour introductory session where they provided baseline demographic and personality data as well as learned how to complete the daily online survey. 
The primary investigator (TBK) guided participants (in small groups) through the definitions of each item, provided a handbook on each item's definition, and gave them a dedicated website to access training instructions or details. Next, he showed each participant how the daily diary data would be stored such that, after discarding the link to their email address, their responses would be anonymous. Finally, he informed participants about research showing certain response biases (e.g., women tend to underreport and men tend to overreport sexual activity) and the importance of honest, accurate recording.

Participants completed surveys online via a secure website devoted to the study before going to sleep each night for three weeks (21 consecutive days). The site included definitions of all study constructs (as previously explained in their baseline training session). To ensure at least two weekends of data, several participants who did not complete surveys during the scheduled weekends that fell during their respective 21-day diary period were asked to record an extra weekend of data. Therefore, several participants had a sequence of days that extended beyond 21 (e.g., 30 days). Researchers sent weekly reminder emails emphasizing compliance, confidentiality, and the time-and-date stamping of online entries. Participants provided an average of 20.75 days of data $(S D=4.91)$. Only four participants provided fewer than 20 valid reports.

\subsection{Global measures}

Relationship Status and Quality. Participants responded to whether they are in a committed romantic relationship (yes or no). To measure relationship longevity, we asked, "How long have you been involved in your romantic relationship?" If in a romantic relationship, participants completed the single-item Inclusion of Other in the Self Scale (IOS; Aron, Aron, \& Smollan, 1992). To best represent feelings of closeness to romantic partners, participants selected one of seven pairs of circles with increasing degrees of overlap, ranging from no contact (1) to almost complete overlap (7). This scale possesses acceptable construct validity, with moderate to large positive correlations with longer measures of relationship functioning (e.g., Aron, Melinat, Aron, Vallone, \& Bator, 1997).

Trait measures. Participants completed the Social Interaction Anxiety Scale (Mattick \& Clarke, 1998) which measures general tendencies to fear and avoid social interactions due to scrutiny concerns. Scale scores reliably discriminate people with social anxiety disorder from other anxiety disorders, and are sensitive to treatment (e.g., Brown et al., 1997).

Participants completed the 21-item Beck Depression Inventory-Second Edition (BDI-II; Beck, Steer, \& Brown, 1996), which assesses the severity of depression symptoms. The BDI-II can reliability distinguish people with and without mood disorders (e.g., Sprinkle et al., 2002).

The Positive and Negative Affect Schedule (PANAS; Watson, Clark \& Tellegen, 1988) consists of two 10-item subscales there were used to ask participants to report on their general positive (e.g., "proud") and negative affect (e.g., "ashamed"), respectively. Prior research has demonstrated that PANAS scores are reliable and valid (e.g., Watson et al., 1988).

Participants completed the 9-item Acceptance and Action Questionnaire (AAQ; Hayes et al., 2004), a self-report measure of the unwillingness to tolerate or experience unpleasant thoughts, feelings, and memories. Prior research provides evidence for the validity of this scale in predicting the onset of emotional disturbances (e.g., Chawla \& Ostafin, 2007).

\subsection{Daily measures}

Sexual assault. At the end of each day, participants responded if they had non-consensual sex today with a binary response option (yes or no). During the face-to-face training session, they 
were informed this referred to any non-consensual sexual act, including unwanted oral, anal or vaginal intercourse, or unwanted touching on any intimate area of a person's body by a sex organ, other body part, or foreign object.

Sexual activity. Each day, participants responded whether they had sex (yes or no); and could report up to six sexual episodes per day. For each sexual episode, they recorded the type of sex had (passionate kissing, oral sex, penetration), feelings of pleasure (1=none to $9=$ very much), and intimacy (using the Inclusion of Other in the Self Scale with a prompt to "indicate the picture below which best describes how close and connected you felt to your partner during sex").

Daily affect. Items from the Positive and Negative Affect Schedule (PANAS; Watson, Clark, \& Tellegen, 1988) used to assess daily mood included four positive emotions (i.e., enthusiastic, happy, satisfied, excited) and four negative emotions (i.e., embarrassed, disappointed, anxious, sad). Participants rated "how well each adjective described their mood today" from $1=$ not at all to $7=$ very much.

Daily meaning in life. Participants were asked, "How meaningful did you feel your life was today", a modified item from the Meaning in Life Questionnaire (Steger, Fraizer, Oishi, \& Kaler, 2006). Participants responded using a Likert scale from $1=$ not at all to $7=$ very much. This singular item of daily meaning has demonstrated acceptable validity (e.g., Kashdan \& Steger, 2007; Steger \& Kashdan, 2013).

Daily self-esteem. We measured daily self-esteem with two items adapted from the Rosenberg Self-Esteem Scale (Rosenberg, 1965) to reflect daily experiences ("Today ... I felt like I had many good qualities", "Today ... on the whole, I was satisfied with myself"). Participants responded to items using a Likert scale from $1=$ not at all to $7=$ very much. These items demonstrated acceptable validity in prior daily diary studies (e.g., Kashdan \& McKnight, 2013; Nezlek \& Plesko, 2001).

Daily social anxiety. Participants answered three questions about social anxiety during the day (i.e., "I worried about what other people thought of me", "I was afraid that others did not approve of $\mathrm{me}^{\text {", }}$ and "I was worried that I would say or do the wrong things") using a 7-point scale from $1=$ not at all to $7=$ very much (Kashdan \& Steger, 2006). Prior work demonstrated the validity of this scale in people with and without social anxiety disorder (Kashdan et al., 2013).

Daily emotion regulation. Participants answered five questions, adapted from the Emotion Regulation Questionnaire (Gross \& John, 2003). Three items captured use of emotion suppression strategies ("I keep my emotions to myself", "When I am feeling positive emotions, I am careful not to express them", and "When I am feeling negative emotions, I make sure not to express them") and two items captured use of cognitive reappraisal ("When I want to feel more positive emotion (such as joy or amusement), I change what I'm thinking about" and "When I want to feel less negative emotion (such as sadness or anger), I change what I'm thinking about") (as used in Kashdan \& Steger, 2006). Participants responded using a Likert scale from $1=$ not at all to $7=$ very much. Prior work has found support for the validity of these scales (e.g., Blalock, Kashdan, \& Farmer, 2016).

\subsection{Data analytic plan}

We treated the data as if we had seven individual $\mathrm{N}$ of 1 studies. In so doing, we were able to look carefully at the idiographic nature of participant responses to daily measures over time. We computed Percent of Maximum Possible scores (POMP; Cohen, Cohen, Aiken \& West, 1999) for each of the six outcomes for all participants. These scores provide a comparable metric between measures (Sechrest, McKnight \& McKnight, 1996). Next, we plotted the individual trajectories of each participant for each outcome to illustrate the change from pre to post sexual assault. 
Due to the nature of small $\mathrm{N}$ studies and the limits to null-hypothesis significance testing (i.e., power), we opted for methods well-established within the psychometric community (Dudek, 1979; Nunally, 1978). We supplemented individual trajectories with an estimate of the standard error of measurement (SEM) for each outcome. SEM is an estimate of the reliable difference in the scale score that can be expected given the test-retest reliability. Values outside two SEMs are traditionally considered beyond the range of plausible true scores. Because this is an exploratory study, we opted to interpret scores + 1 SEM as a useful criterion. We estimated SEM by calculating the intraclass correlation (ICC) for each measure using the entire dataset. The ICC was then used as the reliability estimate over time (rxx) and, as a result, could be used to estimate the SEM (SEM = SD*sqrt(1-rxx)). We considered changes outside one standard error of measurement to be noteworthy whereas changes within that range were expected simply due to scale score unreliability observed in the general, non-assaulted sample. Our use of these metrics merely provide a heuristic for evaluating scores between and within participants - not a definitive statement about the reliability of change or any statistical significance. Finally, we resisted any specific hypothesis testing due to the small sample size and limited a priori hypotheses. We considered all analyses descriptive and exploratory and used these findings to generate hypotheses for future research.

\section{Results}

\subsection{Descriptive data}

Eleven participants endorsed at least one sexual assault episode but four were omitted due to questionable response patterns (see Table 1). We found seven participants who met our inclusion criteria and clearly endorsed sexual assault. The final seven participants (six women, one man) ranged in age from 18 to 22, each identified as heterosexual, five endorsed being in a current romantic relationship (relationship duration ranged from six months to five years), and in terms of race/ethnicity, four were White, two were African-American, and one was Hispanic/Latina.

\subsection{Normalizing values of measures}

We examined each sexual assault survivor's individual difference POMP scores. As a point of comparison, we present the empirical percentiles of survivor's POMP scores in comparison to the rest of the sample who reported no sexual assaults (excluding the four omitted participants mentioned above). Essentially, the subsample with no sexual assaults was treated as a normative comparison. We present the means and standard deviations of the comparison sample in Table 2 (below).

\subsection{Standard error of measurement}

We estimated the standard error of measurement (SEM) for all six outcome measures and established bounds around the pre-event mean for sexual assault survivors as the range of importance when evaluating changes observed over time. Values that fell outside that band of +/- 1 SEM could be viewed as meaningful - at least with respect to the reliability of the measures. The SEM values are in Table 2.

\subsection{Person-level functioning}

We estimated individual trajectories for six outcomes that share some common variance but not enough to warrant any data reduction model. The results of the graphical analyses (see Figures 
1,2 , and 3) and inferences to be drawn are limited - particularly since statistical power is low and causal generalization may be questionable.

Table 2: Descriptive statistics of daily diary outcomes of sexual assault survivors

\begin{tabular}{lccc}
\hline Outcome & Pre-Event Mean & ICC & SEM \\
\hline Positive Affect & 52.47 & 0.44 & 16.54 \\
Negative Affect & 30.66 & 0.36 & 13.89 \\
Self-Esteem & 72.00 & 0.50 & 13.88 \\
Expressive Suppression & & & \\
Cognitive Reappraisal & & 0.57 & 14.69 \\
Social Anxiety & & 0.64 & 17.23 \\
& & 0.50 & 16.50 \\
\end{tabular}

Note. ICC = Intra-class correlations. SEM = Standard error of measurement. Means were from sexual assault survivors. ICC values were computed based upon values observed from the non-assaulted participants only. Values were computed from estimating the variance components from a linear mixed-effects model and using the ratio of variances from a null model. The exact procedures are detailed in Raudenbush and Bryk (2002).

There were few clear patterns observed prior to the event (i.e., sexual assault) nor afterwards for any of the six outcomes. Only a few observations fell outside one standard error of measurement and, as indicated in Figures 1 through 3 (below), most of the data from the identified survivors fell around the grand mean observed from the entire sample. These results indicate that few individual responses were outside what was reported by the non-assaulted sample. Notable exceptions were evident in participant 3 who reported high negative affect and social anxiety outside the range of one standard error of measurement immediately after sexual assault before returning to the sample mean. Interestingly, participant 3's reduction in negative affect and social anxiety converged with a rapid increase in emotional expressive suppression. Participant 2 reported high levels of social anxiety outside the range of one standard error of measurement throughout the post sexual assault assessment period, along with periodic low levels of positive affect and self-esteem outside the range of one standard error of measurement.

\subsection{Normative comparison}

We computed the pooled change process over the 30 days for all non-assaulted participants and provided a reference line (including standard error) in each figure. The included reference line represents the counter-factual to the cases of sexual assault. For all six outcomes, the change over 30 days for these non-assaulted participants were negligible. While the outcomes for these participants produced noteworthy effects - at least for negative and positive affect, self-esteem, 
suppression, and social anxiety - none of these changes were larger than one standard error of measurement.

Figure 1. Trajectory of daily negative affect and social anxiety before and after sexual assaults

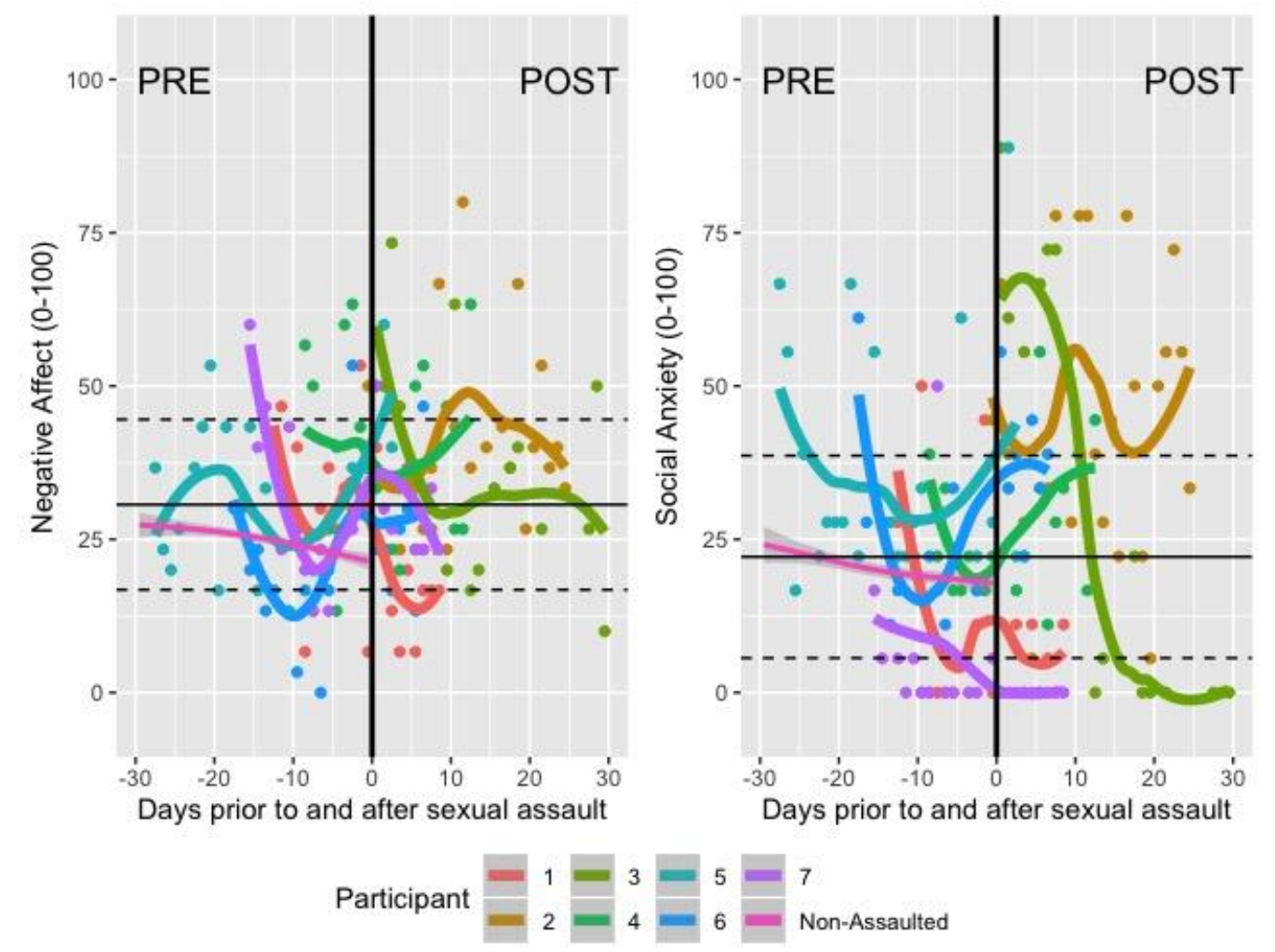

Figure 2. Trajectory of daily positive affect and self-esteem before and after sexual assaults
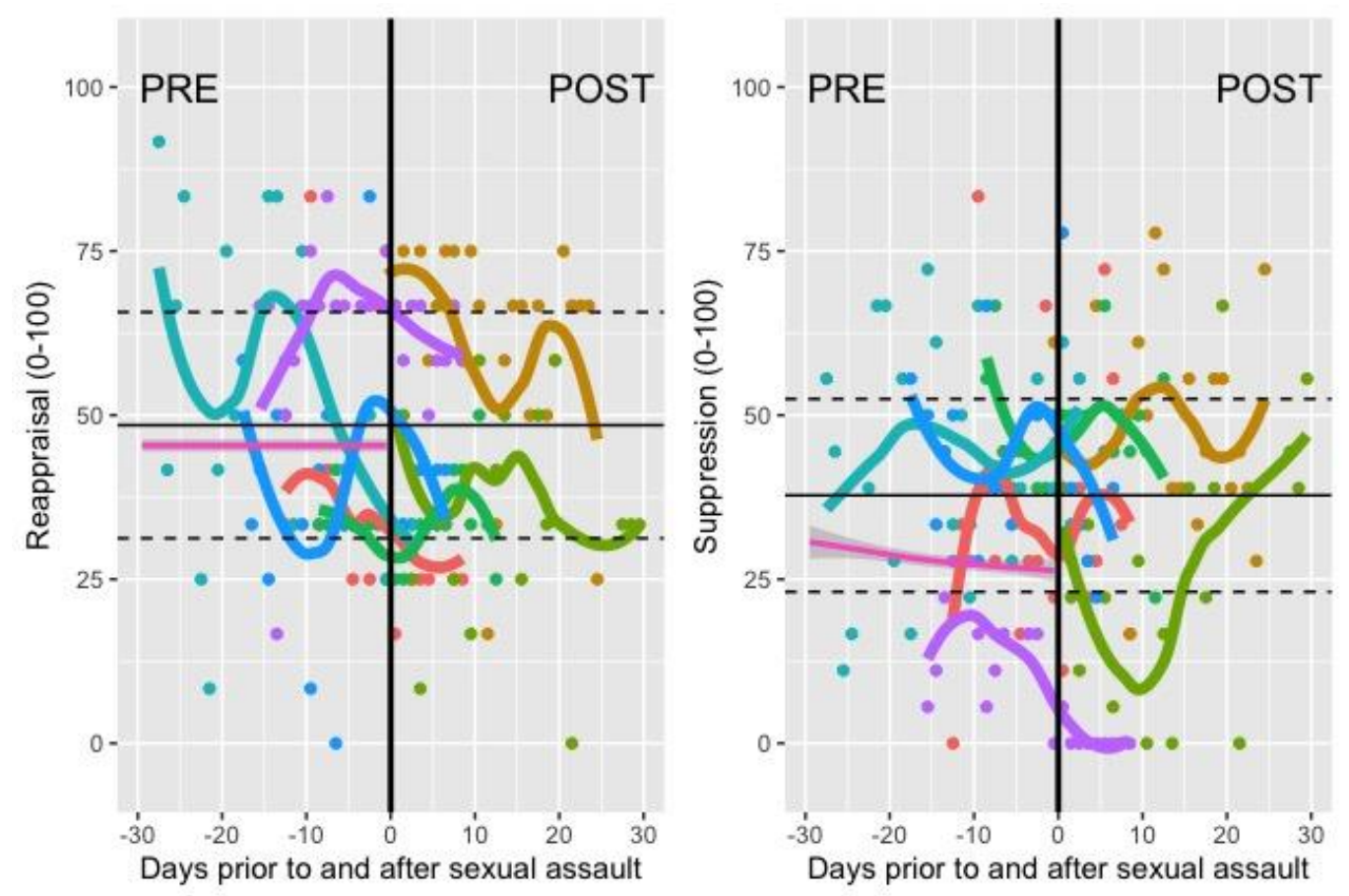

Participant

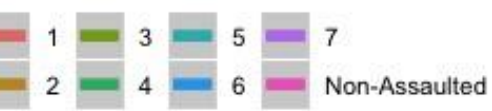


Figure 3. Trajectory of daily emotion regulation strategies before and after sexual assaults
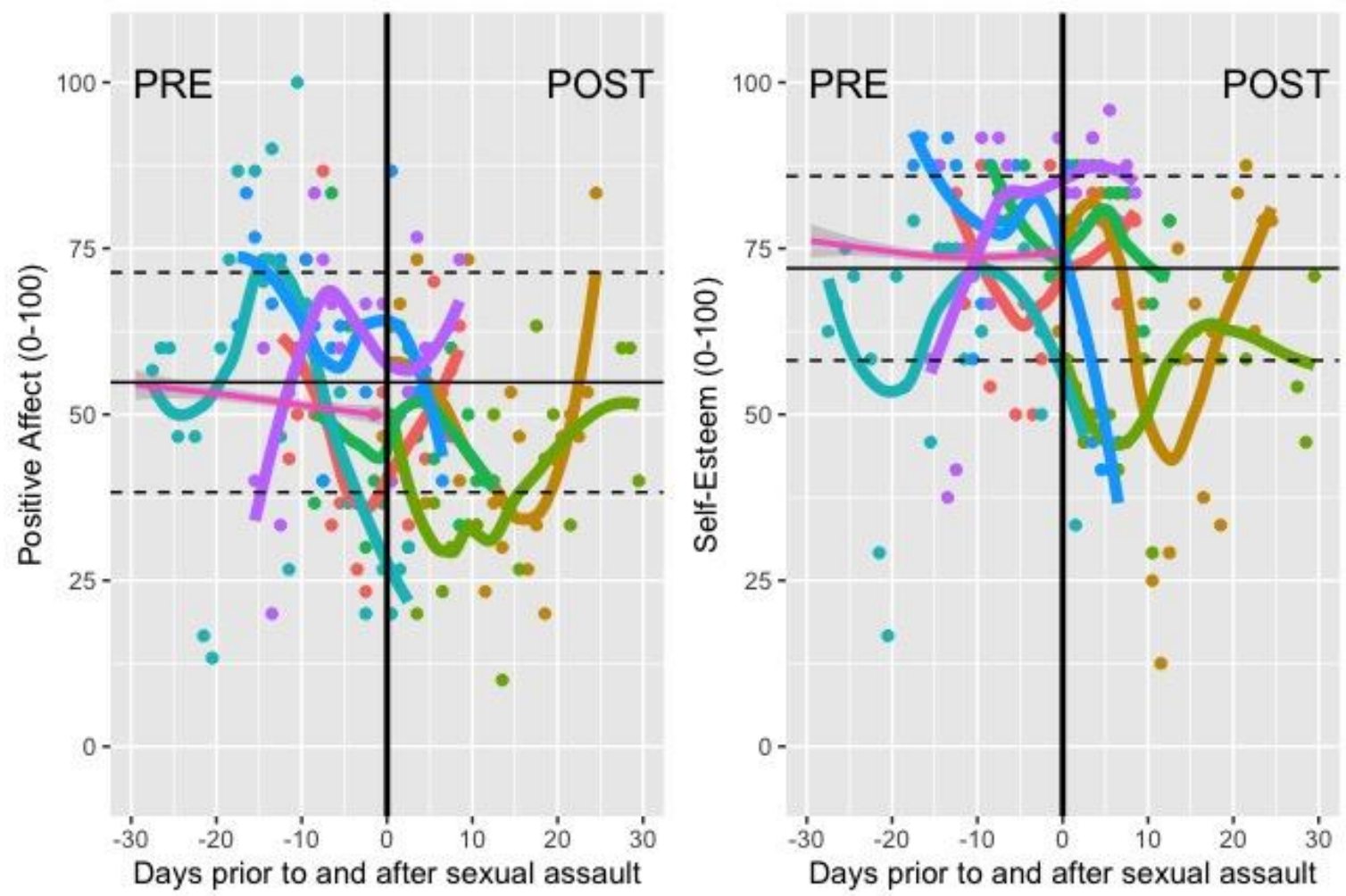

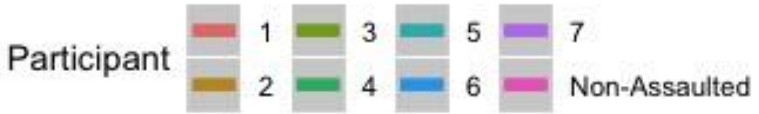

\subsection{Sexual assault vs. normative group}

In all cases, sexually assaulted participants deviated from the normative comparison group prior to the event. The variability of response between sexually assaulted survivors was quite high but all variance fell within one standard error of measurement.

\section{Discussion}

Sexual assault is common in society, with national samples of women leading to estimations of a lifetime prevalence rate of approximately one in five (Breiding et al., 2014; Waechter \& Ma, 2015). Amplifying the societal problem of sexual assault are myths and scripts held about incidents of unwanted, forced sex. When asked to visualize a sexual assault, participants reported, on average, that they expected women to feel. extreme negative emotions afterward, including shame, depression, and a loss of self-esteem (on a rating scale from [1] not at all to [7] completely, each rating was above 6.0; Littleton \& Axsom, 2003). Studies of first line responders (e.g., police officers, detectives) show that survivors tend to be dissatisfied with the inappropriate questions, assumptions, and lack of empathy by interviewers (e.g., Jordan, 2004). For instance, others often view the behavior of a sexual assault survivor as atypical/strange when failing to show overt signs of distress. As a result, other people view them as less credible and attribute more blame to them (e.g., Kaufmann, Drevland, Wessel, Overskeid, \& Magnussen, 2003; Winkel \& Koppelaar, 1991). Taken together, prior research and societal trends warrant scientific research on how people respond in the immediate aftermath of being sexually assaulted and dispel myths about what a prototypical response "should" look like. 
Our research is unlike other published studies. We provided comprehensive within-person data on seven sexual assault survivors with a comparison to a non-assaulted group measured during the same time frame. At first glance, readers might be disinterested because of the small sample size. We ask readers to reconsider the importance of descriptive studies with hard-tocapture samples (Rozin, 2001). Before generating predictions about how people respond to sexual assault, it behooves scientists to begin with exploratory, descriptive data. In our study, we had unprecedented information on subjective well-being on days preceding and days following sexual assault. The only reason we could collect these data is that we included a question about non-consensual sex in a 21-day experience sampling study (Kashdan et al., 2014; Kashdan, Adams, Savostyanova, McKnight \& Nezlek, 2011; Kashdan, Goodman, Stiksma, Milius, \& McKnight, 2018). When data are available to capture the temporal course of traumatic events (see Fredrickson, Tugade, Waugh, \& Larkin, 2003 for an examination of 46 people before to after the terrorist attacks on September 11, 2001), a small sample becomes meaningful, especially if the goal is to provide knowledge to spearhead future research.

To ensure high-quality data, the principal investigator (TBK) (1) met with every participant to explain the anonymity of sexual data reporting, (2) showed participants how responses would appear in the database to research personnel (i.e., rows of data without identifying information), (3) provided definitions of each construct - including non-consensual sex, and (4) reviewed existing research that shows women's tendency to underreport and men's tendency to overreport sexual activity. This labor-intensive strategy prior to data collection reduces self-presentation concerns and increases the quality of information provided for a stigmatized topic such as sexual activity. We offer these details to provide behavioral evidence of the integrity of the data presented on seven sexual assault survivors.

We were interested in one question: how do people's psychological functioning change immediately following sexual assault? With daily data from seven sexual assault survivors, we found that on average, prior to being assaulted, people experienced a decline in well-being. There was no discernible pattern across sexual assault survivors. In the days immediately after the sexual assault, several survivors showed a rapid decline in well-being, others showed little to no change, and others show a slight increase in well-being.

How can we make sense of the various reactions to surviving sexual assault? Our study is not able to provide the answers and thus, provide several hypotheses for future research to test.

1. How sexual assault survivors cope in the short-term often includes strategies that are generally deemed maladaptive such as avoidance, suppression, dissociation, and exaggerated self-enhancement (e.g., Bonanno, 2005; Ozer, Best, Lipsey, \& Weiss, 2003). Protecting yourself defensively with exaggerated self-enhancement and positive illusions is may be more important in the immediate aftermath of trauma than making accurate self-assessments. The world does not stop after being assaulted. Survivors might still have to deal with the stressors and responsibilities of daily life: childcare, paid work, schooling, friends, family, romantic partners, and/or home maintenance as well as potentially interact with their assaulters. Attempts to avoid, suppress, or dissociate at the time of the sexual assault are common and relatively effective for surviving the ordeal. In the immediate and short-term these functional survival strategies could lead to the artificial and faulty conclusion that sexual assault increases well-being. Emotion regulation research suggests that strategies aimed to disengage from current distress may provide short-term reprieve that ultimately comes at the expense of longer-term psychological functioning (Aldao, Nolen-Hoeksema, \& Schweizer, 2010). More work is needed on the strategies deployed by sexual assault survivors from prior to being assaulted, during the 
assault, and the temporal course afterwards-including a detailed analysis of when strategies are and are not functional, and in what ways do sexual assault survivors rigidly stick to strategies long beyond their functional value.

2. Any short-term increase in well-being in sexual assault survivors being studied might reflect posttraumatic growth. The value of descriptive data is illustrating the wide range of complexities in human behavior that are often overlooked when focusing on sample means. Extreme events might lead to extreme changes. We might assume sexual assault only leads to extreme adverse changes. Yet, in the immediate aftermath of sexual assault, a survivor can discover how much care and validation friends, family, and romantic partners offer, or a recognition of strengths that are deployed in challenging circumstances (such as courage, perseverance, or forgiveness) (e.g., Elderton, Berry, \& Chan, 2017; Ulloa, Guzman, Salazar, \& Cala, 2016). At first pass, the idea of posttraumatic growth might seem invalidating or dismissive of the pain caused by a trauma. To the contrary, posttraumatic growth offers a hopeful perspective on trauma by suggesting that trauma survivors may gain something positive from the trauma despite or because of the pain it caused. This hypothesis of "strength through suffering" is akin to the redemptive value of suffering found in many religious teachings. Janoff-Bulman (2004) reported that one sexual assault survivor shared with her, "I feel much stronger now ... Part of that rape was to dominate and humiliate me, and he didn't succeed at that. I came through with my integrity-I got through those months of hell." In a small subset of survivors, posttraumatic growth following sexual assault might emerge rapidly.

3. On a descriptive level, some sexual assault survivors appear to show signs of declining well-being prior to the sexual assault. Questions arise as to whether people with compromised well-being are at increased risk of being the target of predators. There is evidence that sexual abusers are more likely to seek out potential victims according to psychological markers of vulnerability including low self-worth, loneliness, and emotional disturbances (e.g., Wolak, Finkelhor, Mitchell, \& Ybarra, 2010). To be very clear and explicit: by no means are we attributing any blame to sexual assault survivors. Instead, we point out a research question as to whether a dynamic decline in well-being is noticeable to sexual predators and used to target specific individuals. Markers of low energy, insufficient social resources, and unsatisfied psychological needs might signal vulnerability that sexual predators aim to prey upon. More work is needed from the lens of existing and potential sexual assault perpetrators to understand who they pick out, who they dismiss as targets, and why. This knowledge can assist prevention and intervention efforts. We know that people are more likely to be assaulted by someone they know (Jones, Wynn, Kroeze, Dunnuck, \& Rossman, 2004). It is possible that the downward trend of well-being prior to being assaulted is the result of grooming by an abusive romantic partner (or family member, friend, neighbor, or colleague).

4. Our work also raises issues about measurement. While all participants received the same training on the definition of terms, their rating and meaning system might have changed in the aftermath of sexual assault. In the absence of cognitive interviews or think aloud paradigms (e.g., Davison, Navarre, \& Vogel, 1995), we simply do not know whether their definition of low, medium, and high positive affect, self-esteem, and other well-being features changed. We might hypothesize that for some survivors, a contrast effect emerged such that the threshold for experiencing a good or even exceptional day lowered after an incident of sexual assault. We cannot assume that the measures operate the same 
if a person changes in the aftermath of sexual assault. Perhaps our data suggesting a slight increase in well-being after sexual assault is a measurement artifact. Future research would benefit from mixed-method designs that incorporate qualitative data collection, which can help illuminate the meaning of participant's quantitative responses.

Our results are provocative, if only because of the transparency of the temporal sequence of what seven people experienced in days leading up to a sexual assault and their responses afterwards. In the absence of a larger sample size assessing coping strategies deployed and whether attitudes, beliefs, behavior, and personality changed, we are left with questions on the heterogeneity of sexual assault survivors. It is important to add an interpretative caveat that we did not followup with survivors directly about the sexual assault after it happened (e.g., how survivors felt about the assault) or in the long-term. As with most studies of traumatic events, our interpretations are limited to data about processes that are assumed to be related to sexual assault, but in the absence of direct questions about the assault, cannot be guaranteed. Questions remain as to how survivors' daily well-being operates weeks later and the percentage that show recovery versus resilience (e.g., Bonanno, 2013; Steenkamp et al., 2012). In sum, our data are descriptive, not predictive.

Future work would benefit from a wide range of potential moderators including the degree of sexual interaction during the assault or non-consensual sex, whether the perpetrator was known and if so what type of relationship existed, and the context of the event (e.g., psychological coercion, physical incapacitation from alcohol or drugs, threat or use of physical force). With respect to survivors who displayed minimal immediate distress, it would be valuable to collect (informant) data from individuals close to the survivor (e.g., parent, romantic partner, friend, roommate) and compare these trajectories to how survivors of assaults report their well-being. A larger sample will allow for such examinations of whether there are meaningful person and situational variables that influence well-being trajectories.

Despite the small sample, the results have conceptual and policy relevant implications by questioning the idea of a prototypical profile of survivors. Some survivors in our sample reported being emotionally distraught, others reported no discernible change in emotional disturbances and well-being, whereas others' reports suggested they outwardly appeared to be healthywhich for some, might be the result of effectively deployed avoidance strategies to cope with the sexual assault and maintain a semblance of day-to-day functioning. We hope these data initiate new research and help end judgments rendered on sexual assault survivors based on whatever psychological state emerges when discussing the incident, a day, week, month, or years later. As with any stressor, people will likely experience and display diverse responses to sexual assault. By moving beyond explorations of mean/average reactions, researchers can refine existing conceptual models of survivors for practitioners and policy makers.

\section{Conflict of interest statement}

The authors report no conflicts of interest.

\section{Authors}

Todd B. Kashdan

George Mason University

tkashdan@gmu.edu

Patrick E. McKnight

George Mason University 
David J. Disabato

George Mason University

Kerry C. Kelso

George Mason University

MarLa Lauber

George Mason University

Fallon R. Goodman

George Mason University

\section{Publishing Timeline}

Received 22 June 2020

Accepted 5 July 2020

Published 1 October 2020

\section{References}

Alper, N. O., \& Wassall, G. H. (2006). Artists' careers and their labor markets. In V. A. Ginsburg, \& D. Throsby (Eds.), Handbook of the economics of art and culture (pp. 813-864) Elsevier. https://doi.org/10.1016/S1574-0676(06)01023-4

Aldao, A., Nolen-Hoeksema, S., \& Schweizer, S. (2010). Emotion-regulation strategies across psychopathology: A meta-analytic review. Clinical Psychology Review, 30, 217-237. https://doi.org/10.1016/j.cpr.2009.11.004

Andersen, S. B., Karstoft, K.-I., Bertelsen, M., \& Madsen, T. (2014). Latent trajectories of trauma symptoms and resilience: The 3-year longitudinal prospective USPER study of Danish veterans deployed in Afghanistan. The Journal of Clinical Psychiatry, 75, 1001-1008. https://doi.org/10.4088/JCP.13m08914

Aron, A., Aron, E., \& Smollan, D. (1992). Inclusion of Other in the Self Scale and the structure of interpersonal closeness. Journal of Personality and Social Psychology, 63, 596-612. https://doi.org/10.1037/0022-3514.63.4.596

Aron, A., Melinat, E., Aron, E., Vallone, R., \& Bator, R. (1997). The experimental generation of interpersonal closeness: A procedure and some preliminary findings. Personality and Social Psychology Bulletin, 23, 363-377. https://doi.org/10.1177/0146167297234003

Beck, A.T., Steer, R.A., \& Brown, G.K. (1996). Manual for the Beck Depression Inventory-II. San Antonio, TX: Psychological Corporation. https://doi.org/10.1037/t00742-000

Berntsen, D., Johannessen, K. B., Thomsen, Y. D., Bertelsen, M., Hoyle, R. H., \& Rubin, D. C. (2012). Peace and war: Trajectories of posttraumatic stress disorder symptoms before, during, and after military deployment in Afghanistan. Psychological Science, 23, 1557-1565. https://doi.org/10.1177/0956797612457389

Blalock, D., Kashdan, T.B., \& Farmer, A.S. (2016). Trait and daily emotion regulation in social anxiety disorder. Cognitive Therapy and Research, 40, 416-425. https://doi.org/10.1007/s10608-015-9739-8

Bonanno, G. A. (2005). Resilience in the face of potential trauma. Current Directions in Psychological Science, 14, 135-138. https://doi.org/10.1111/j.0963-7214.2005.00347.x

Bonanno, G. A. (2013). How prevalent is resilience following sexual assault?: Commentary on Steenkamp et al. (2012). Journal of Traumatic Stress, 26, 1-2. https://doi.org/10.1002/jts.21803

Breiding, M., Smith, S., Basile, K., Walters, M., Chen, J., \& Merrick, M. (2014). Prevalence and characteristics of sexual violence, stalking, and intimate partner violence: Victimization - National Intimate Partner and Sexual Violence Survey, United States, 2011. Morbidity and Mortality Weekly Report: Surveillance Summaries, 63, 1-18. 
Brown, E. J., Turovsky, J., Heimberg, R. G., Juster, H. R., Brown, T. A, \& Barlow, D. H. (1997). Validation of the Social Interaction Anxiety Scale and the Social Phobia Scale across the anxiety disorders. Psychological Assessment, 9, 21-27. https://doi.org/10.1037/1040-3590.9.1.21

Campbell, R., Sprague, H. B., Cottrill, S., \& Sullivan, C. M. (2011). Longitudinal research with sexual assault survivors: A methodological review. Journal of Interpersonal Violence, 26, 433-461. https://doi.org/10.1177/0886260510363424

Campbell, R., Dworkin, E., \& Cabral, G. (2009). An ecological model of the impact of sexual assault on women's mental health. Trauma, Violence, \& Abuse, 10, 225-246. https://doi.org/10.1177/1524838009334456

Carey, K. B., Norris, A. L., Durney, S. E., Shepardson, R. L., \& Carey, M. P. (2018). Mental health consequences of sexual assault among first-year college women. College Health, 66, 480-486. https://doi.org/10.1080/07448481.2018.1431915

Chawla, N., \& Ostafin, B. (2007). Experiential avoidance as a functional dimensional approach to psychopathology: An empirical review. Journal of Clinical Psychology, 63, 871-890. https://doi.org/10.1002/jclp.20400

Cohen, P., Cohen, J., Aiken, L. S., \& West, S. G. (1999). The problem of units and the circumstance for POMP. Multivariate Behavioral Research, 34, 315-346. https://doi.org/10.1207/S15327906MBR3403_2

Davison, G. C., Navarre, S. G., \& Vogel, R. S. (1995). The articulated thoughts in simulated situations paradigm: A think-aloud approach to cognitive assessment. Current Directions in Psychological Science, 4, 29-33. https://doi.org/10.1111/1467-8721.ep10770963

Dickstein, B. D., Suvak, M., Litz, B. T., \& Adler, A. B. (2010). Heterogeneity in the course of posttraumatic stress disorder: trajectories of symptomatology. Journal of Traumatic Stress, 23, 331-339. https://doi.org/10.1002/jts.20523

Diener, E. (1984). Subjective well-being. Psychological Bulletin, 95, 542-575. https://doi.org/10.1037/00332909.95.3.542

Dudek, F. J. (1979). The continuing misinterpretation of the standard error of measurement. Psychological Bulletin, 86, 335-337. https://doi.org/10.1037/0033-2909.86.2.335

Dworkin, E. R., Menon, S. V., Bystrynski, J., \& Allen, N. E. (2017). Sexual assault victimization and psychopathology: A review and meta-analysis. Clinical Psychology Review, 56, 65-81. https://doi.org/10.1016/j.cpr.2017.06.002

Dworkin, E. R., Ullman, S. E., Stappenbeck, C., Brill, C. D., \& Kaysen, D. (2018). Proximal relationships between social support and PTSD symptom severity: A daily diary study of sexual assault survivors. Depression and Anxiety, 35, 43-49. https://doi.org/10.1002/da.22679

Elderton, A., Berry, A., \& Chan, C. (2017). A systematic review of posttraumatic growth in survivors of interpersonal violence in adulthood. Trauma, Violence, $\mathcal{E}$ Abuse, 18, 223-236. https://doi.org/10.1177/1524838015611672

Frazier, P., Conlon, A., \& Glaser, T. (2001). Positive and negative life changes following sexual assault. Journal of Consulting and Clinical Psychology, 69, 1048-1055. https://doi.org/10.1037/0022006X.69.6.1048

Fredrickson, B. L., Tugade, M. M., Waugh, C. E., \& Larkin, G. R. (2003). What good are positive emotions in crisis? A prospective study of resilience and emotions following the terrorist attacks on the United States on September 11th, 2001. Journal of Personality and Social Psychology, 84, 365-376. https://doi.org/10.1037/0022-3514.84.2.365

Goodman, F. R., Disabato, D. J., Kashdan, T. B., \& Machell, K. A. (2017). Personality strengths as resilience: A one-year multiwave study. Journal of Personality, 85(3), 423-434. https://doi.org/10.1111/jopy.12250

Gross, J. J., \& John, O. P. (2003). Individual differences in two emotion regulation processes: Implications for affect, relationships, and well-being. Journal of Personality and Social Psychology, 85, 348-362. https://doi.org/10.1037/0022-3514.85.2.348

Hayes, S. C., Strosahl, K., Wilson, K. G., Bissett, R. T., Pistorello, J., Toarmino, D., . . McCurry, S. M. (2004). Measuring experiential avoidance: A preliminary test of a working model. The Psychological Record, 54, 553-578. https://doi.org/10.1007/BF03395492 
Infurna, F. J., \& Luthar, S. S. (2018). Re-evaluating the notion that resilience is commonplace: A review and distillation of directions for future research, practice, and policy. Clinical Psychology Review, 65, 43-56. https://doi.org/10.1016/j.cpr.2018.07.003

Janoff-Bulman, R. (2004). Posttraumatic growth: Three explanatory models. Psychological Inquiry, 15(1), 30-34.

Jayawickreme, E., \& Blackie, L. E. (2014). Post-traumatic growth as positive personality change: Evidence, controversies and future directions. European Journal of Personality, 28, 312-331. https://doi.org/10.1002/per.1963

Jones, J. S., Wynn, B. N., Kroeze, B., Dunnuck, C., \& Rossman, L. (2004). Comparison of sexual assaults by strangers versus known assailants in a community-based population. The American Journal of Emergency Medicine, 22(6), 454-459. https://doi.org/10.1016/j.ajem.2004.07.020

Jordan, J. (2004). Beyond belief? Police, rape and women's credibility. Criminal Justice, 4, 29-59. https://doi.org/10.1177/1466802504042222

Kashdan, T. B., Adams, L. M., Farmer, A. S., Ferssizidis, P., Mcknight, P. E., \& Nezlek, J. B. (2014). Sexual healing: daily diary investigation of the benefits of intimate and pleasurable sexual activity in socially anxious adults. Archives of Sexual Behavior, 43, 1417-1429. https://doi.org/10.1007/s10508-0130171-4

Kashdan, T. B., Adams, L. M., Savostyanova, A., Ferssizidis, P., Mcknight, P. E., \& Nezlek, J. B. (2011). Effects of social anxiety and depressive symptoms on the frequency and quality of sexual activity: A daily process approach. Behaviour Research and Therapy, 49, 352-360. https://doi.org/10.1016/j.brat.2011.03.004

Kashdan, T. B., Farmer, A. S., Adams, L. M., Ferssizidis, P., Mcknight, P. E., \& Nezlek, J. B. (2013). Distinguishing healthy adults from people with social anxiety disorder: Evidence for the value of experiential avoidance and positive emotions in everyday social interactions. Journal of Abnormal Psychology, 122, 645-655. https://doi.org/10.1037/a0032733

Kashdan, T. B., Goodman, F. R., Stiksma, M., Milius, C. R., \& Mcknight, P. E. (2018). Sexuality leads to boosts in mood and meaning in life with no evidence for the reverse direction: A daily diary investigation. Emotion, 18, 563-576. https://doi.org/10.1037/emo0000324

Kashdan, T. B., \& McKnight, P. E. (2011). Dynamic, contextual approaches to studying personality in the social world. Journal of Personality, 79, 1177-1190. https://doi.org/10.1111/j.1467-6494.2011.00737.x

Kashdan, T. B., \& Mcknight, P. E. (2013). Commitment to a purpose in life: An antidote to the suffering by individuals with social anxiety disorder. Emotion, 13, 1150-1159. https://doi.org/10.1037/a0033278

Kashdan, T. B., \& Steger, M. (2006). Expanding the topography of social anxiety: An experience-sampling assessment of positive emotions, positive events, and emotion suppression. Psychological Science, 17, 120-128. https://doi.org/10.1111/j.1467-9280.2006.01674.x

Kashdan, T. B, \& Steger, M. (2007). Curiosity and pathways to well-being and meaning in life: Traits, states, and everyday behaviors. Motivation and Emotion, 31, 159-173. https://doi.org/10.1007/s11031007-9068-7

Kaufmann, G., Drevland, G. C., Wessel, E., Overskeid, G., \& Magnussen, S. (2003). The importance of being earnest: Displayed emotions and witness credibility. Applied Cognitive Psychology, 17, 21-34. https://doi.org/10.1002/acp.842

Kilpatrick, D.G., Resnick, H.S., Ruggiero, K.J., Conoscenti, L.M., McCauley, J. (2007). Drug-facilitated, incapacitated, and forcible rape: A national study. National Institute of Justice. (Final report submitted to the National Institute of Justice [NCJ 219181]). Washington, DC: U.S. Department of Justice, National Institute of Justice. https://doi.org/10.1037/e667182007-001

Krahé, B., \& Berger, A. (2017). Gendered pathways from child sexual abuse to sexual aggression victimization and perpetration in adolescence and young adulthood. Child Abuse and Neglect, 63, 261-272. https://doi.org/10.1016/j.chiabu.2016.10.004

Littleton, H. L., \& Axsom, D. (2003). Rape and seduction scripts of university students: Implications for rape attributions and unacknowledged rape. Sex Roles, 49, 465-475.

https://doi.org/10.1023/A:1025824505185 
Mancini, A. D., Littleton, H. L., \& Grills, A. E. (2016). Can people benefit from acute stress? Social support, psychological improvement, and resilience after the Virginia Tech campus shootings. Clinical Psychological Science, 4, 401-417. https://doi.org/10.1177/2167702615601001

Mattick, R. \& Clarke, J. (1998). Development and validation of measures of social phobia scrutiny fear and social interaction anxiety. Behaviour Research and Therapy, 36, 455-470. https://doi.org/10.1016/S0005-7967(97)10031-6

Murphy, S. M., Amick-McMullan, A. E., Kilpatrick, D. G., Haskett, M. E., Veronen, L. J., Best, C. L., \& Saunders, B. E. (1988). Rape victims' self-esteem: A longitudinal analysis. Journal of Interpersonal Violence, 3, 355-370. https://doi.org/10.1177/088626088003004001

Nash, W. P., Boasso, A. M., Steenkamp, M. M., Larson, J. L., Lubin, R. E., \& Litz, B. T. (2015). Posttraumatic stress in deployed Marines: Prospective trajectories of early adaptation. Journal of Abnormal Psychology, 124, 155-171. https://doi.org/10.1037/abn0000020

Naragon-Gainey, K., Simpson, T., Moore, S., Varra, A., \& Kaysen, D. (2012). The correspondence of aggregated daily PTSD symptom reports and retrospective report: Examining the roles of symptom instability, PTSD symptom clusters, and depression symptoms. Psychological Assessment, 24, 10411047. https://doi.org/10.1037/a0028518

Nezlek, J. B., \& Plesko, R. (2001). Day-to-day relationships among self-concept clarity, self-esteem, daily events, and mood. Personality and Social Psychology Bulletin, 27, 201-211. https://doi.org/10.1177/0146167201272006

Nunnally, J. C. (1978). Psychometric theory. New York: McGraw-Hill.

Ozer, E. J., Best, S. R., Lipsey, T. L., \& Weiss, D. S. (2003). Predictors of posttraumatic stress disorder and symptoms in adults: a meta-analysis. Psychological Bulletin, 129, 52-73. https://doi.org/10.1037/00332909.129.1.52

Raudenbush, S.W., Bryk, A.S. (2002). Hierarchical linear models: applications and data analysis methods (2nd Ed.). Thousand Oaks: Sage Publications.

Rosenberg, M. (1965). Society and the adolescent self-image. Princeton, New Jersey: Princeton University Press. https://doi.org/10.1515/9781400876136

Rozin, P. (2001). Social psychology and science: Some lessons from Solomon Asch. Personality and Social Psychology Review, 5, 2-14. https://doi.org/10.1207/S15327957PSPR0501_1

Sechrest, L., McKnight, P.E., \& McKnight, K. (1996). Calibration of measures for psychotherapy outcome studies. American Psychologist, 51, 1065-1071. https://doi.org/10.1037/0003-066X.51.10.1065

Stappenbeck, C. A., Hassija, C. M., Zimmerman, L., \& Kaysen, D. (2015). Sexual assault related distress and drinking: The influence of daily reports of social support and coping control. Addictive behaviors, 42, 108-113. https://doi.org/10.1016/j.addbeh.2014.11.013

Steenkamp, M. M., Dickstein, B. D., Salters-Pedneault, K., Hofmann, S. G., \& Litz, B. T. (2012). Trajectories of PTSD symptoms following sexual assault: Is resilience the modal outcome? Journal of Traumatic Stress, 25, 469-474. https://doi.org/10.1002/jts.21718

Steenkamp, M. M., Litz, B. T., Dickstein, B. D., Salters-Pedneault, K., \& Hofmann, S. G. (2013). What is the typical response to sexual assault? Reply to Bonanno (2013). Journal of Traumatic Stress, 26, 394-396. https://doi.org/10.1002/jts.21804

Steger, M., Frazier, P., Oishi, S., \& Kaler, M. (2006). The meaning in life questionnaire: Assessing the presence of and search for meaning in life. Journal of Counseling Psychology, 53, 80-93. https://doi.org/10.1037/0022-0167.53.1.80

Steger, M., \& Kashdan, T. B. (2013). The unbearable lightness of meaning: Well-being and unstable meaning in life. The Journal of Positive Psychology, 8, 103-115. https://doi.org/10.1080/17439760.2013.771208

Tedeschi, R. G., \& Calhoun, L. G. (1996). The Posttraumatic Growth Inventory: Measuring the positive legacy of trauma. Journal of Traumatic Stress, 9, 455-471. https://doi.org/10.1002/jts.2490090305

Thurston, R. C., Chang, Y., Matthews, K. A., von Känel, R., \& Koenen, K. (2018). Association of sexual harassment and sexual assault with midlife women's mental and physical health. JAMA Internal Medicine, 179, 48-53. https://doi.org/10.1001/jamainternmed.2018.4886 
Ulloa, E., Guzman, M. L., Salazar, M., \& Cala, C. (2016). Posttraumatic growth and sexual violence: A literature review. Journal of Aggression, Maltreatment \& Trauma, 25, 286-304. https://doi.org/10.1080/10926771.2015.1079286

Waechter, R., \& Ma, V. (2015). Sexual violence in America: public funding and social priority. American Journal of Public Health, 105, 2430-2437. https://doi.org/10.2105/AJPH.2015.302860

Watson, D., Clark, L. A., \& Tellegen, A. (1988). Development and validation of brief measures of positive and negative affect: The PANAS scales. Journal of Personality and Social Psychology, 54, 1063-1070. https://doi.org/10.1037/0022-3514.54.6.1063

Westphal, M., \& Bonanno, G. A. (2007). Posttraumatic growth and resilience to trauma: Different sides of the same coin or different coins?. Applied Psychology, 56, 417-427. https://doi.org/10.1111/j.14640597.2007.00298.x

Winkel, F. W., \& Koppelaar, L. (1991). Rape victims' style of self-presentation and secondary victimization by the environment: An experiment. Journal of Interpersonal Violence, 6, 29-40. https://doi.org/10.1177/088626091006001003

Wolak, J., Finkelhor, D., Mitchell, K. J., \& Ybarra, M. L. (2010). Online "predators" and their victims: Myths, realities, and implications for prevention and treatment. Psychology of Violence, 1, 13-35. https://doi.org/10.1037/2152-0828.1.S.13 